\title{
ALGUNOS APUNTES Y REFLEXIONES ANTE UNA NUEVA ETAPA DE LA PSICOLOGÍA CLÍNICA COMO ESPEGIALIDAD SANITARIA DE LA PSICOLOGÍA
}

[Publicada la orden ministerial (pre/1107/2002 de 10 de mayo) por la que se regulan las vías transitorias de acceso al título de especialista en psicología clínica en desarrollo de lo dispuesto en el real decreto 2490/98 de 20 de noviembre (b.o.e. $n^{2} 119,18$ de marzo de 2002)]

\section{BEGOÑA OLABARRÍA}

Presidenta de la Comisión Nacional de la Especialidad de Psicología Clínica, Ministerio de Sanidad y Ministerio de Educación

(Aceptado en junio de 2002)

Casi nadie pone en duda que los valores que con tanto esfuerzo construyó y defendió el discurso y el que-hacer de los principios de la reforma sanitaria (Ley General de Sanidad) y de la reforma psiquiátrica son valores de la modernidad en lo sanitario y que, por tanto, cuentan con un ascendiente incorporado e incuestionable entre los profesionales y también en la administración pública.

Seguramente de ellos y también de la visualización de las «nuevas» demandas y necesidades en el ámbito sanitario deviene la publicación de la orden ministerial publicada en el BOE del 18 del pasado mes de mayo que abre el proceso de operativización del Real Decreto 2498/98 por el que se cre6 y reguló la Psicología Clínica como especialidad sanitaria de la Psicología, con la homologación de títulos.

Estos valores que se reconocen en la racionalidad (y generosidad) de la publicación de dicha Orden Ministerial, tan largamente buscada, permiten mejorar la asistencia sanitaria a través, en este caso, de la oficialización como especialidad de un saber que viene aportando su conocimiento y hacer científicos. Mencionar

Correspondencia: Begoña Olabarría, Francisco de Diego 3, 28040 Madrid. aquí la generosidad viene a destacar la esencial contribución de quienes, desde fuera de la psicología (políticos, gestores, psiquiatras, médicos de diferentes especialidades, asociaciones de diferentes ámbitos de conocimiento, etc.), han configurado unos apoyos sin los cuales seguramente el ingente trabajo desarrollado por la mayor parte de la comunidad científico-profesional de la psicología durante años, no habría dado el fruto que hoy hemos alcanzado.

Naturalmente frente a la confianza en la perfectibilidad de las instituciones y sus modos de hacer, en los saberes científicos y sus aplicaciones especializadas, en la universalidad de la razón, en la necesidad de un reconocimiento oficial de lo que se configura como un hecho científico y social incontrovertible, como es la Psicología Clínica, se han alzado poderosos detractores y enemigos que han venido arguyendo que sin el modelo médico tradicional y la protección de los sistemas de creencias y poderes jerarquizados gremialmente de los saberes, el caos y el desorden sustituirían al orden y al cosmos sanitario (mito, que, no por serlo, configura un discurso resistente de alto potencial, como las muchas actuaciones que devienen del mismo han venido a demostrarnos). 
Estamos en una cultura y un medio social en que las distintas profesiones, en función de la dialéctica social en la que están incluidas, defienden sus intereses y valores como públicos. Pero hoy lo público está marcado por el pluralismo y por ende por el relativismo. Así, cada colectivo científico-profesional está obligado ya no sólo por sus códigos instrumentales y de conocimiento, sino también por el respeto al pluralismo y a la valoración relativa de sus propios principios y fundamentos en el marco de dinámicas sociales cambiantes movidas por contradicciones.

Además, pero no menos importante, no contamos ya hoy con el principio de verdad absoluta en los ámbitos públicos, y las ciencias aplicadas son uno de éstos. Sus instrumentos estarán legitimados operativamente si se engarzan en discursos de concepciones y de orientación de la dinámica social en diferentes líneas, de establecimiento de ideas, objetivos y prioridades basadas en éticas colectivas.

Ahora, alcanzado el techo de la oficialización de la especialidad de la Psicología Clínica con la orden ministerial publicada, cabe asumir la evidencia de que ninguna especialidad sanitaria es ajena a otra. Evidencia que, a mi juicio, nos obliga aún más a hacer efectivo el quehacer interdisciplinar para hacer posible la comprensión del sentido integral de la atención sanitaria dirigida a la complejidad multidimensional del ser humano en su contexto. Los prejuicios provenientes de la cultura sanitaria donde el «modelo médico» continúa haciendo predominante el dominio biologicista, reduccionista, jerárquico, compartimentador y simplificador, no están únicamente fuera, en quienes tomaron posiciones más abiertas o más tibias en contra de la creación de esta Especialidad sanitaria. Creo que tenemos la obligación de alertarnos acerca de la posibi- lidad de que algunos de dichos prejuicios (y sus correspondientes lecturas y propuestas) estén también entre nosotros, entre quienes compartimos la satisfacción de ver publicada la orden ministerial: La definición de fronteras excluyentes, compartimentadoras, en el quehacer profesional, en los equipos, contienen ese germen $y$, con él, sus riesgos.

Los bloques herméticos entre ciencias cuyas fronteras resultan extremadamente vigiladas para la evitación de entradas («instrusismos») en los campos de aplicación o experienciales, han sido históricamente permeables en los desarrollos conceptuales. Como señala Morin (1986) es preciso prestar atención a las modalidades de esta circulación de conceptos para poder sustituir anexiones y sojuzgamientos de conceptos (y sus aplicaciones) por circulaciones reflexivas. Del entramado de lenguajes plurales que puedan articularse en distintos niveles de investigación/intervención, tal vez deviene un nuevo modo de hacer conocimiento.

También se ha puesto en crisis la estricta separación entre lo psíquico y lo físico o corporal. Que el modelo conceptual bio-psico-social no sea (aún) predominante en los campos de intervención de la Psicología Clínica (y de la Salud...), seguramente tiene que ver con la necesidad de mostrar (y demostrar) su capacidad operativa, su adaptabilidad creativa en los sistemas sanitarios, su demostración de la intervención de específicas variables psicológicas aparte de las biológicas en el delicado equilibrio procesual salud/enfermedad, de la posibilidad de intervención en dicho proceso desde la Psicología (también sobre variables físicas) y todo ello de manera complementaria a otras profesiones y campos de investigación/ acción en organizaciones sanitarias complejas. 
El problema estriba en que el saber enciclopédico por un solo hombre dejó de ser posible a finales del siglo XVIII y que resulta obligada la profesionalización, en base a una disciplina o determinado campo de conocimiento, como ejercicio aplicado de las disciplinas especializadas sobre campos de intervención comunes y complejos. Pero decir que la realidad social es un todo y que en ella cada elemento está relacionado con los demás no es más que decir un lugar común. Tal vez un paso más a dar estaría en avanzar, en hallar desde cada disciplina especializada que interviene en campos de intervención comunes a otras, en qué consisten esas relaciones y conceptualizarlas más que entrar en guerras fronterizas entre especialistas en que cada uno parece más bien empujar fuera del campo a los otros acusándoles de invasores y al tiempo señalándoles cuál es el lugar que a ellos corresponde y dentro del cuál les autoriza actuar.

La suposición de que la naturaleza de nuestras actuaciones profesionales como psicólogos clínicos puede englobarse en un sistema perfectamente definido y acabado es una equivocación: Nuestros discursos sobre nosotros mismos no somos nosotros mismos. Se trata de una condición siempre en formací́n, como el conocimiento - del que puede formar parte- $y$ por tanto nunca completa. Podemos con nuestros discursos además sugerir una pseudorealidad consistente en dibujar la creencia de que somos algo fijo si creemos y transmitimos que los lugares definidos y en los que nos situamos para relacionarnos con los "otros» pueden sustituirnos a nosotros mismos.

Se trata de la creencia consistente en creer en la inexistente existencia de una segunda naturaleza profesional que vendría dada por lo que "ocupamos» y no por lo que somos, con sus contradiccio- nes y sus ambigüedades, con sus aportaciones, pero también con sus carencias.

Las definiciones de estas segundas naturalezas son sencillas, elementales casi, claras y coherentes. Pero contienen el peligro de confundir la ilusión con la realidad, el mapa con el territorio (lo que, a mi juicio, no es un riesgo sólo para los profesionales de la Psicología, naturalmente).

Creo importante pensar en la naturaleza disputada del quehacer profesional como aplicación del conocimiento, en el que no se establecen las fronteras de los patrimonialismos corporativos. Pensar en el reconocimiento del papel que podemos desempeñar en la formación de nuestras propias identidades y en las de los otros, y los dilemas que ese reconocimiento plantea para la comprensión de un quehacer que quiere contribuir a generar una atención integral y contextualizada, en la comunidad, y por tanto con «otros» saberes.

La práctica de la unidad de la razón clásica dio paso a lenguajes plurales y con ello a lo que Rella ha definido como la búsqueda de una nueva razón de la pluralidad, del entramado de lenguajes plurales que articulan un nuevo modo de "hacer conocimiento". Desde esta perspectiva, la necesidad de pensar la diferencia se actualiza en la interdisciplinariedad situándose frente a la «ideología de la pertenencia (Flores d'Arcais, 1994) que apuesta por el regreso de las supuestamente inmutables viejas esencias corporativas, cerradas y empobrecedoras.

Pero el respeto a la diferencia que reclama la interdisciplinariedad tiene también sus riesgos en sus aplicaciones prácticas: Las buenas intenciones pueden sesgarse y convertirse en menosprecios. Hay respetos que matan. Es lo que ocurre en los equipos multiprofesionales y en las comunidades científi- 
co-profesionales cuando el derecho a ser diferente se compra (o se paga) con una correspondiente indiferencia. Se instala entonces entre los distintos saberes una recíproca indiferencia que impide poder respetar y discutir al mismo tiempo, enjuiciar sin ofender, ofrecer razones $\mathrm{y}$ opciones sin hacer como aquél que en vez de dar datos, daba con datos. Se trata a mi juicio de una tesis ilusoria y peligrosa por falseadora de la realidad. La tesis de que no nos comprendemos heterónimamente es poco plausible.

Por otra parte, el respeto a las diferencias de los saberes exige espacios de significación compartidos y conocidos, aunque sea cierto que nos expone a una cierta forma de vulnerabilidad saludable. Dicho de otro modo, para que un discurso científico-profesional pueda ser considerado moralmente independiente y socialmente competente, la relación con su contexto habría seguramente de tener ciertas características: (1) Estar fundamentado, teniendo consistencia y coherencia internas. (2) Ser apropiado para aquello de lo que dice ocuparse. (3) Estar presentado con un cierto rigor que de cuenta del respeto a la audiencia. $Y$ algo más (4), ofrecer oportunidades que permitan que se cuestione la conciencia sobre ese lugar. Se trata de añadir a la definición de sentido, la posibilidad de su refutación, de su crítica o debate con otros. Se trata de evitar también el riesgo de confundir los rasgos del propio saber con los del "mundo». Se trata, en definitiva, de facilitar homo y heterocredibilidad.

El enfoque multidisciplinar en los problemas de salud es ya una realidad fruto de la necesidad de abordar la incidencia de múltiples variables imposibles de aprehender desde una única disciplina. Hoy, es la necesidad de dar respuestas integrales a problemas complejos lo que obliga a un referente interdisciplinar.
Pero la interdisciplinaridedad obliga en términos operativos a la interprofesionalidad, a la consideración de los modos de integración de las prácticas y teorías de los profesionales que contienen y por$\tan$ los saberes. La consideración del respeto mutuo, entre los distintos saberes y sus aplicaciones desde el objetivo de la interdisciplinariedad se convierte en una prioridad para una atención integral, pero también desde el reconocimiento de que cada saber y cada profesión no pueden dar cuenta de la integralidad. Creo que el respeto de los otros no está en el "que cada cual actúe por su cuenta", sino en los modos de investigaciónacción más integrales para abordar la complejidad.

La interpretación romántica de la razón y la ciencia, incluidas las ciencias sociales en su entrelazamiento con las ideologías, según la cual se establece la creencia en la existencia de una sola verdad científico/profesional y por tanto la falsedad de todo aquello que con dicha "verdad" no coincidiera, resultaría de este modo ser uno de los peligros que están en la base de los sofisticados modos patrimonialistas y corporativos de hacer en los campos de intervención.

Resulta así precisa la búsqueda rigurosa del reconocimiento simétrico complementario de las distintas disciplinas que operan en los equipos multiprofesionales y que, complementaria y recíprocamente han de integrar estrategias de intervención y de investigación.

De este modo, por interdisciplinariedad podemos entender una estrategia grupal que implica un abordaje o visión coordinada entre disciplinas y/o profesiones con fronteras o límites mantenidos de modo permeable favoreciendo intercambios mutuos y parciales integraciones de sus aportaciones respectivas (Sánchez Vidal, 1991). Su meta estaría en la consecución de intervenciones 
más integrales desde la aceptación de la complejidad de lo que ha de ser abordado (atención, investigación) y sus objetivos generales cubrirían un amplio abanico: abordar necesidades, resolver demandas, tomar decisiones planificadas, investigar de modo más comprensivo, programar, intervenir, formar de manera más global.

Otro aspecto a tomar en consideración y que no podemos olvidar en el marco de una crisis de los valores del Estado del Bienestar, es la incorporación de nuevas herramientas en el Sistema Nacional de Salud -que, previsiblemente, no han hecho más que iniciarse-, como los nuevos modelos de gestión que establecen nuevos parámetros: eficacia y eficiencia, equidad, accesibilidad, separación entre el aseguramiento público y la provisión de servicios, establecimiento de contratos sanitarios, introducción de la competencia interservicios, etc. De dicha incorporación se vienen desprendiendo modos y criterios que afectarán a la organización de las intervenciones en los servicios y que, en cualquier caso, anuncian importantes cambios en el campo de la salud, lo que a la Psicología Clínica en sus aplicaciones afectará seguramente de maneras difícilmente previsibles. Por ello, el cercano seguimiento de los nuevos modelos de gestión y sus implicaciones se configura como una de las nuevas y obligadas líneas de actuación a establecer por los especialistas - y las organizaciones en las que participan- en la búsqueda de garantías para el mejor desarrollo de las aplicaciones adecuadas de esta especialidad y en su articulación con otras.

Por último, pero no menos importante, es preciso ahora (más aún que antes, si cabe) mantener la exigencia de excelencia profesional en la cobertura de plazas en el Sistema Nacional de Salud $y$, por ello, que las plazas en los servi- cios sanitarios para el ejercicio de la Psicología Clínica se contemplen desde el perfil del PIR, si queremos que la calidad sea un elemento central de la gestión de personal y de las prestaciones. Alerta que sin duda conviene sostener ante la Administración Pública, alejándonos de los intereses particulares e inmediatistas (que también se juegan entre nosotros).

La Psicología Clínica en España -pese a importantes resistencias externas e internas- puede (ahora, desde el nuevo estatus que le confiere la Orden Ministerial que acaba de publicarse) y debe contribuir a generar ese necesario espacio para la mejora en las prestaciones, que, aunque a veces parece estar entre nosotros, otras parece encontrarse lejos y aún defenestrado. No debemos acomodarnos en la confortable espera de un futuro mejor porque la idea de progreso continuado es falsa. Se trataría de una ilusión, como la de quienes esperando a Godot. (Beckett, 1956) para la solución de sus problemas dicen: «...¿qué estamos haciendo aquí, ésta es la cuestión. Y lo maravilloso es que sabemos la respuesta. Sí, en esta inmensa confusión sólo una cosa es clara. Estamos esperando a que llegue Godot».

Iniciemos ahora una nueva etapa cerrando la anterior con la homologación de títulos para los profesionales en ejercicio. Tratemos todos de hacerlo responsablemente. A ello dirigirá sus esfuerzos la Comisión Nacional de la Especialidad de Psicología Clínica que (verdaderamente, sin formalismos) me honro en presidir.

\section{REFERENCIAS BIBLIOGRÁFICAS}

Morin, E. (1986). El método. La naturaleza de la naturaleza. Madrid:Catedra. 
Flores d'Arcais, E. (1994). El desafío oscurantista. Madrid: Anagrama.

Sanchez Vidal, A. (1.991). Interdisciplinariedad y acción social. En III
Jornadas de Psicologia de la Intervención Social (Tomo I). Madrid: COP.

Beckett, S. (1956). Esperando a Godott. Madrid: Austral. 